\title{
Studies on the Reproduction and Growth of Hoopoe (Upupa epops) in District Gujrat, Punjab, Pakistan
}

\author{
Muhammad Idnan ${ }^{1, *}$, Hafiz Muhammad Jamil2, Arshad Javid³, Muddasir Hassan Abbasi4 ${ }^{4}$, Muhammad Altaf ${ }^{5}$, Asif \\ Shahzad², Asma Naeem ${ }^{1}$ \\ 'Department of Zoology, University of Central Punjab, Lahore, Pakistan \\ 2Department of Zoology, Minhaj University, Lahore, Pakistan \\ ${ }^{3}$ Department of Wildlife and Ecology, University of Veterinary and Animal Sciences, Lahore, Pakistan \\ ${ }^{4}$ Department of Zoology, University of Okara, Okara, Pakistan \\ ${ }^{5}$ The University of Azad Jammu and Kashmir, Muzaffarabad, Azad Jammu and Kashmir, Pakistan
}

\section{ABSTRACT}

Background: Hoopoe, Upupa epops belongs to the family Upupidae. It is found across Asia, Europe and Africa. Its habitat includes grasslands, savannas, wooded steppes, and forests. Main threats to the survival of the Hoopoe are habitat loss and climate changes.

Objectives: The present study was planned in district Gujrat $\left(32.7037^{\circ} \mathrm{N}, 73.9585^{\circ} \mathrm{E}\right)$, Punjab Pakistan. Due to habitat loss and cutting of Sheesham tree (Dalbergia sissoo), the natural nesting sites was very scarce.

Methodology: Thirty three nested sites of Hoopoe were spotted and checked for chick's presence regarding timing and breeding at the interval of one week. Egg size was measured using Dial clipper and weighed with electrical weighing balance.

Results: The percentage clutch size $7.04 \pm 0.64$, brood size $1.76 \pm 0.70$ and nesting success of $81 \%$ was recorded. The following trees provided the nesting sites as hole/cavities Ficus benghalensis (Barh) (23.5\%), Dalbergia sissoo (Shisham) (35.2\%), Acacia nilotica (Kikar) (11.7\%), Ficus religiosa (Peepal) (14.7\%), Mangifera indica (Mango) (8.8\%).

Conclusion: More trees should be planted and wooden nest boxes should be provided at the human dwellings so that they can coexist with man.

$\begin{array}{lll}\text { Keywords } & \text { *Address of Correspondence } & \text { Article info. } \\ \text { Hoopoe, Nesting, Habitat, Breeding, } & \text { adnan264@gmail.com, } & \text { Received: June 27, 2019 } \\ \text { Reproductive Success, Conservation. } & \text { muhammad.idnan@uvas.edu.pk } & \text { Accepted: January 17, 2020 }\end{array}$

Cite this article: Idnan M, Jamil HM, Javid A, Abbasi MH, Altaf M, Shahzad A, Naeem A. Studies Funding Source: Nil on the Reproduction and Growth of Hoopoe (Upupa epops) in District Gujrat, Punjab, Pakistan. Conflict of Interest: Nil RADS J Biol Res Appl Sci. 2019;10(2):102-108.

This is an Open Access article distributed under the terms of the Creative Commons Attribution License (http://creativecommons.org/licenses/by/4.0), which permits unrestricted use, distribution, and reproduction in any medium, provided the original work is properly cited.

\section{INTRODUCTION}

Hoopoe (Upupa epops) commonly known as "Hudhud" in Pakistan, belongs to the family called Upupidae. Distribution range of this magnificent bird include across Asia, Africa, Europe and Madagascar. It is found in forests, grasslands, savannas, wooded steppes and widely distributed in agricultural lands. In Holy Qura'an, Hoopoe is described as a courtier of Prophet Hazrat Sulayman (A.S) and in ancient Egypt it is considered as a sacred bird. By IUCN, Hoopoe is listed as a "least concerned" species, but its population is decreasing generally by over hunting, habitat loss and degradation. Main causes for this include, human construction activities, climatic changes and/or availability of food resources. Eight sub species of Hoopoe are found in Asia, Sub-Saharan Africa and Madagascar. It is commonly observed that Hoopoe is nesting in holes of tree barks, old buildings, abandoned places, drainpipes, nest boxes or wells etc. Hoopoe may use same nest for several 
season as a nesting site. In Hungary, during the year 2015, it was declared as the "Bird of the Year" which elaborates its importance for conservation priorities 1 .

It lays egg in late April or in early May in Southern and Central Europe, but in canaries it lay eggs in January. It primarily preys on insects and their larvae/pupae or on other small invertebrates. Hoopoe is territorial breeder, pair as monogamous and live solitary, in some places it also shows extra-pair paternity2. Population growth in Hoopoe is related with rate, survival of juveniles and fecundity, this reflects that the demographic components affecting the migration of individuals in a population are playing a vital role in population dynamics than the demographic components ${ }^{3}$. Breeding dispersal in Hoopoe is more common among bird species, (as female disperse more as compare to male Hoopoes) and this dispersal is somewhat affected by age or previous breeding history of the female 4 . After agriculture intensification and the use of insecticides, which reduces the availability of insects (as the Hoopoe is insectivorous bird), the reproductive success is greatly affected ${ }^{5}$. Therefore, due to the scarcity of food and habitat loss, the population of Hoopoe is declining, thus, for future conservation the use of insecticides should be minimize, and artificial nest boxes should be provisioned.

Upupa epops is a good example of a bird that searches food on the ground. Important cues for breeding habitat selection can be food availability, availability of nest sites, and presence of mates, predation risk, or combinations thereof. A good breeding home range offers all kinds of resources (e.g. food, partners, nest sites, shelters from predators) in enough supply. If one of the required resources is lacking or insufficient, the reproductive output would be comparatively low, i.e. the home range is suboptimal $^{6}$. Because food is usually patchily distributed within a home range, different parts of the home range are not used evenly. Other resources being equal, results in increased visiting of places with high amount of food than places where food is scarce or of lower quality. If food resources are dense and clumped, the size of the home range can be small, with an excellent costs/benefits ratio favoring reproductive output ${ }^{7}$. Roosting in closed sites, such as cavities in winter provides more thermal benefits $^{8}$ and better protection from predators ${ }^{9-10}$ than roosting in open sites such as tree limbs. In human- altered landscapes where natural tree cavities may be limited, some secondary cavity nesting species use other available closed roost sites such as human-made structures, e.g. barns, sheds, or abandoned buildings, and nest boxes as roosts in the nonbreeding season ${ }^{11}$.

Therefore, although nest boxes are typically posted to increase breeding productivity, nest boxes may also create important roost sites that lead to improved overwintering survival and beneficial population-level effects. Nest boxes should be placed to cope with an increasing rate of deforestation. This will be helpful to provide the more nesting sites to Hoopoe with an increase in population. The effectiveness of nest box programs as a management tool typically necessitates that nest boxes either decrease nest site limitation or create improved productivity relative to natural cavities ${ }^{12}$. Without careful placement, nest boxes may become ecological traps ${ }^{13}$.

Despite a well-documented preference for open and semiopen farmland, the precise microhabitat requirements of Hoopoe's are still poorly understood. This lack of information hampers the formulation of appropriate conservation action plans. The main goal of this study was to assess patterns of reproduction, habitat selection and foraging in population of Hoopoe's in Gujrat, Punjab, Pakistan.

\section{MATERIALS \& METHODS}

Thirty-three (33) nests of Hoopoe were spotted by observing the parents with binoculars (10x50) (Nikon cooperation) from a suitable distant vantage point; the help of local shepherds/nomads was also being taken in locating the nests and the nests encountered accidentally. The nests were checked for chick's presence regarding timing and success of breeding, at interval of one week; care was taken to record the data without disturbing the pairs. The egg size was measured with dial caliper and weight with electric balance. The annual reproductive success (ARS) of the Hoopoe was calculated by following Murray (2000)14. The comparison of ARS was made between the populations of the Hoopoe during the study period.

\section{Study Area and Data Collection}

The Hoopoe (Upupa epops) is a good example of a bird that searches for food (mainly arthropods) on the ground 
and is secondary cavity nesting bird 15 . The present study was conducted in district Gujrat $\left(32.7037^{\circ} \mathrm{N}, 73.9585^{\circ} \mathrm{E}\right)$, Punjab, Pakistan. Nests were checked on weekly basis. To check the brood phenology and breeding success the nests were visited after an interval of three days, to get comprehensive information of a nest. Breeding birds were captured from their nest after the chicks were of six days by mist nets and cavity entrance trap or by grabbing a brooding female in her nest. Captured individuals were sexed either by plumage color or by prominent uropygial gland on female.

The nest success and egg success were calculated as follows:

Nest success $=$ No. of clutches that produce young $/$ Total number of clutches

Egg success $=$ No. of young that leave the nest $/$ Total number of eggs

\section{Diet of Nestlings}

During the study period of January 2016 to April 2017, the prey items brought to the nests by parents were noted in about 10 nests with considerable efforts. The study on breeding population was carried out with help of binoculars and cameras. To feed chicks, parent bird was observed to bringing a single type (species) of insects. For chick feeding, mostly a single item of prey was observed, brought to the nests by parent. Sometimes it was difficult to recognize a prey due to the position of bird's bill with orientation to nest opening.

\section{Nest Location \& Reproductive Success}

The data for young fledged was recorded for possible nests. Data on same site over next brooding site was independent of the next recordings during the study period.

\section{RESULTS}

In total, 33 nest sites were examined to study nesting behavior of Hoopoe. In the study area, main tree sites observed by Hoopoe for nesting were Ficus benghalensis (Barh) (23.5\%), Dalbergia sissu (Shisham) (35.2\%), Acacia nilotica (Kikar) (11.7\%), Ficus religiosa (Peepal)
(14.7\%), Mangifera indica (Mango) (8.8\%), that provide more suitable nesting cavities/holes.

During the study, 33 nests were observed in different locations of study area. The nesting sites were located in building pipes (42.4\%), building walls $(24.2 \%)$ and cutting banks (33.3\%). Table 1 shows the detail of nesting sites as holes for Hoopoe. Banyan fig (Ficus benghalensis) 23.5\%, Sheesham (Dalbergia sissu) 35.2\%, Gum arabic (Acacia nilotica) 11.7\%, Bodhi tree (Ficus religiosa) $14.7 \%$ and in Mango (Mangifera indica) $8.8 \%$. The maximum hole nests were found in Sheesham (Dalbergia sissu) as $35.2 \%$, and minimum in Mango (Mangifera indica) i.e., $8.8 \%$.

Table 1. Nesting Sites Used by Hoopoe in Trees.

\begin{tabular}{lcc}
\hline \multicolumn{3}{c}{ Hole Nesting Used by Hoopoe on Trees } \\
\hline Tree Species & $\begin{array}{c}\text { No. of } \\
\text { Trees (N) }\end{array}$ & $\%$ \\
\hline Banyan fig (Ficus benghalensis) & 08 & 23.5 \\
\hline Sheesham (Dalbergia sissu) & 12 & 35.2 \\
\hline Gum arabic (Acacia nilotica) & 4 & 11.7 \\
\hline Bodhi tree (Ficus religiosa) & 5 & 14.7 \\
\hline Mango (Mangifera indica) & 3 & 8.8 \\
\hline
\end{tabular}

The percentage of hole nesting used by Hoopoe on building sites (Table 2) was $42.4 \%$ in building pipes, $24.2 \%$ in building walls and $33.3 \%$ in cutting edges. Parameters of nesting sites with their complete characterization is mentioned in Table $\mathbf{3}$.

Table 2. Hole Nesting Used by Hoopoe on Building Sites in Study Area (Gujrat).

Hole Nesting Used by Hoopoe on Building Sites

\begin{tabular}{cccc}
\hline S. No. & Tree Species & N & $\%$ \\
\hline 1 & Building pipes & 14 & 42.4 \\
\hline 2 & Building walls & 08 & 24.2 \\
\hline 3 & Cutting edges & 11 & 33.3 \\
\hline
\end{tabular}


Table 3. Nesting Sites and Habitat Characteristics of Hoopoe in Gujrat District, Province Punjab-Pakistan.

\section{S. No. Parameters of Nesting Sites $(\mathrm{cm} / \mathrm{m})$}

Characteristics of Nesting Sites (Mean \pm SD)

\begin{tabular}{clcc}
\hline 1 & Height of nesting $(\mathrm{m})$ & $3.3 \pm 1.43$ & $8.9 \pm 1.40$ \\
\hline 2 & Nest location $(\mathrm{m})$ & $5.1 \pm 0.15$ & $6.3 \pm 1.27$ \\
\hline 3 & Nest Diameter $(\mathrm{cm})$ & $19.4 \pm 2.32$ & $23.2 \pm 9.0$ \\
\hline 4 & Hole/Cavity Depth $(\mathrm{cm})$ & $40.4 \pm 2.53$ & $46.4 \pm 13.74$ \\
\hline 5 & Number of nest sites & $1.5 \pm 0.22$ & $1.4 \pm 0.51$ \\
\hline 6 & Distance to nearest tree $(\mathrm{m})$ & $2.8 \pm 0.23$ & $3.1 \pm 2.21$ \\
\hline 7 & Distance to Agricultural lands $(\mathrm{m})$ & $12.1 \pm 0.21$ & $88.3 \pm 30.12$ \\
\hline 8 & Distance to Water Source $(\mathrm{m})$ & $15.9 \pm 2.62$ & $19.5 \pm 6.41$ \\
\hline 9 & Distance to nearest human Dwellings $(\mathrm{m})$ & $71.2 \pm 1.23$ & $49.5 \pm 12.34$ \\
\hline 10 & Distance to Nearest buildings $(\mathrm{m})$ & $31.2 \pm 1.37$ & $34.0 \pm 9.41$ \\
\hline 11 & Distance to Nearest roads $(\mathrm{m})$ & $78.2 \pm 1.24$ & $70.2 \pm 18.41$ \\
\hline
\end{tabular}

Table 4. Clutch and Brood Size and Nesting Success of Hoopoe in the Study Area.

\begin{tabular}{ccccc}
\hline \multirow{2}{*}{ Year } & Nest Sites & Clutch Size & Brood Size & \multirow{2}{*}{ Nesting Success (\%) } \\
\cline { 2 - 4 } & & Mean \pm SD & Mean \pm SD & \\
\hline 2016 & 14 & $7.03 \pm 0.63$ & $1.8 \pm 0.57$ & 67 \\
\hline 2017 & 10 & $7.1 \pm 0.58$ & $1.6 \pm 0.86$ & 67 \\
\hline Total & 24 & $7.04 \pm 0.64$ & $1.76 \pm 0.70$ & 81 \\
\hline
\end{tabular}

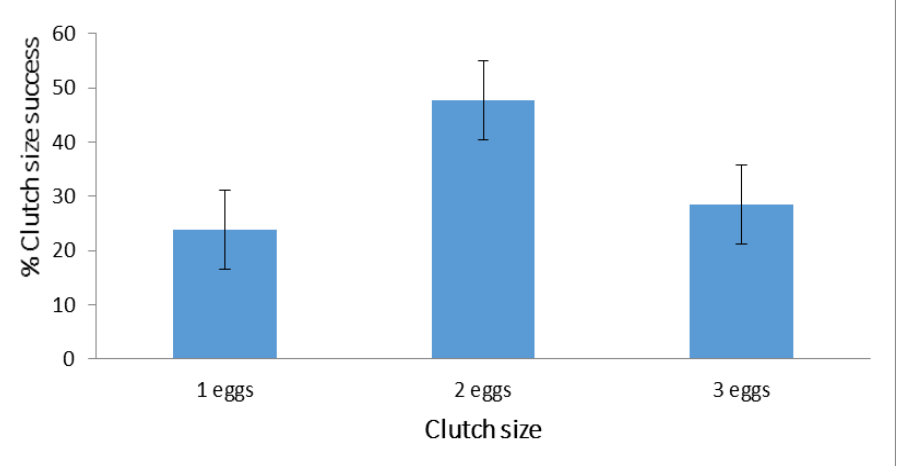

Figure 1. Percentage of Clutch size in Hoopoe during the study period of 2016-17 in Gujrat, Punjab, Pakistan. 
A total of 24 nesting sites were observed 14 in the year 2016 and 10 in 2017 survey. The clutch size was $7.03 \pm$ 0.63 and $7.03 \pm 0.63$; brood size was $1.8 \pm 0.57$ and 1.6 \pm 0.86 with nesting success of $81 \%$ during the study period (Table 4; Figure 1).

For the hatching and fledging success of Hoopoe, a total of 43 eggs were laid by Hoopoe during the study period of 2016-17 (Table 5). Out of 31 eggs hatched, 25 young fledged with an average fledging success of 81 percent. nestlings produced after each reproductive attempt. Predation often affects the reproductive success by causing nest loss and the rate of predation is directly related to the type of nest used for breeding, hole-nesting species. Hole nesting species mostly face less predation rate as compared to the open nester species ${ }^{19}$. This is the reason that hole-nesting birds tend to invest their energy on one or two large clutches instead of several small ones and the only reason for a larger clutches and more broods

Table 5. Hatching and Fledging Success of Hoopoe in the Study Area Gujrat During 2016 and 2017.

\begin{tabular}{cccccc}
\hline Year & $\begin{array}{c}\text { Total No. of } \\
\text { Eggs Laid }\end{array}$ & $\begin{array}{c}\text { Total No. of Eggs } \\
\text { Hatched }\end{array}$ & $\begin{array}{c}\text { Hatching Success } \\
(\%)\end{array}$ & $\begin{array}{c}\text { No. of Young } \\
\text { Fledged }\end{array}$ & $\begin{array}{c}\text { Fledging Success } \\
\text { (\%) }\end{array}$ \\
\hline 2016 & 24 & 19 & 79 & 14 & 74 \\
\hline 2017 & 19 & 12 & 63 & 11 & 92 \\
\hline Total & 43 & 31 & 72 & 25 & 81 \\
\hline
\end{tabular}

\section{DISCUSSION}

Hoopoe (Upupa epops), a hole nesting bird prefer to inhabit trees as mentioned in Table 1 and wall cavities in farmlands where they can forage on insects ${ }^{16}$. They are also found in thin or cleared forests, and use multiple habitats due to their bimodal distribution i.e. they can adjust them in open fields and in forests as well ${ }^{17}$. Hoopoe provides food items to the brooding female and nestlings for first week of incubation. After this period both parents participate for feeding to nestlings but female feeds to young nestling after receiving the prey items from male. Hoopoe are residing in variety of hole-nests, mainly located below $3 \mathrm{~m}$ in height, such a height is accessible for some predators like snakes, small mammals or lizards etc., (Table 2 and 3). Nestlings of Hoopoe have developed anti-predatory mechanism by the production of copious amount of faeces and bad-smelling fluid from oil glands.

Normally Hoopoes lay on average 7 eggs with an interval of 24 hours and in rare cases of 48hours interval (Table 4). Incubation is started after first or second egg is laid. Hatching is asynchronous with an interval of 24hours, in contrast to this, hatching in African sub-species is entirely synchronous $^{18}$.

Avian reproductive success is related with the number of breeding attempt and on the number of successful than expectations to the open nesters. It is suggested that this special reproductive pattern of such non-excavator species is related with availability of the suitable nesting sites to have a more reproductive success when more secure nesting holes are available. Basically, the efficiency of a reproductive success depends on the clutch size and the number of eggs reared by the pair. When sufficient food resources are available Hoopoe increase their clutch size by laying more eggs so that they could easily rear their nestlings ${ }^{20}$. In wild habitat the Hoopoe's are entirely insect eating birds, they use their long beak to explore insects for their meals. Mostly the Hoopoe's feed on waxworms, mealworms, crickets and other available insects as a food source ${ }^{21}$.

Hoopoe's pair for a single season, are monogamous and territorial birds. Male show his ownership for a territory by advertising calls. The male calls frequently to advertise his ownership of the territory. Dominancy is established by chasing and fight between males, which occasionally results in blindness in males and bills are used to stab the competitors. Sometimes females also fight for males. Mostly, the nest is located in hole of a tree or a wall with narrow entrance. Only female incubates eggs. In current study, the clutch size recorded was about 7 eggs with a weight of 4.5 grams.

Reproductive success is a crucial factor which drives the population dynamics of Hoopoe and most probably the 
second clutch is an important parameter of its reproductive success. Therefore, variations in double brooding behavior of Hoopoe contribute a potential role in population dynamics of a Hoopoe. Some preliminary studies on double brooding behavior of Hoopoe describe a positive effect on egg laying date with strophe length of male songs and the chances of second clutch production, however no distinction in fledging numbers of first and second clutch ${ }^{22}$. The incubation period of Hoopoe is about 15-18 days; it starts after the first egg laying. Thus, chicks produced are asynchronous. Chicks hatch with a downy feather which turn to adult feathers after three to five days. The chicks also excrete a foul-smelling liquid from uropygial gland; probably to distract the predator. Female brood chicks for 9-14 days and male bring food to the nest, after this period female also join the male for food gathering. After 26-29 days the young fledge and remain for one week more with parents for grooming.

It is recommended that the survival of Hoopoe and other birds in study area of Gujrat, Panjab, Pakistan, be ensured by providing them nest boxes, planting more trees, reducing the deforestation rate and minimizing the use of insecticides. A further detailed research is recommended on breeding behavior, Hoopoe's prey insects' distribution and ecology of Hoopoe and insects for a biological control mechanism on vast agricultural intensification practices in country.

\section{CONCLUSION}

Hoopoes Upupa epops, once a commonly found bird in various areas of Pakistan, is now facing a decline in its population. Timely reproduction of an individual is primarily determined by its reproductive success which in turn is governed by availability of habitat, nesting sites, availability of food resources and seasonal fluctuations in an area. With increasing constriction activities, intensive use of insecticides and rapid deforestation, the timing and conditions of migration and reproductive performance of Hoopoe and other birds has been affected. Further studies should be conducted to determine the changes in resources availability and how the reproductive performance of these birds should be increased to enhance the population size of Hoopoe, so it might be used as an effective component in agriculture to control insect's population in biological control.

\section{ACKNOWLEDGEMENT}

The authors are thankful to for all contributors and others from where the literature was cited.

\section{CONTRIBUTORS STATEMENT}

Muhammad Idnan involved in manuscript drafting and research work, Muddasir proof read the manuscript, Asif Shahzad and Jamil conducted field survey for this study. Arshad Javid supervised the research project and approved the final draft and Asma Naeem contributed for technical help.

\section{LIST OF ABBREVIATIONS}

SD

IUCN

ARS
Standard Deviation

International Union for Conservation of Nature

\section{Annual Reproduction Success}

\section{REFERENCES}

1. Krištín A, Kirwan G. Common Hoopoe (Upupa epops). Handbook of the Birds of the World Alive. Lynx Edicions, Barcelona (retrieved from http://www.hbw.com/node/55871 on 25 February 2015); 2014.

2. Martín-Vivaldi M, Martínez JG, Palomino JJ, Soler M. Extrapair paternity in the Hoopoe Upupa epops: An exploration of the influence of interactions between breeding pairs, non-pair males and strophe length. Ibis. 2002; 144(2):236-47.

3. Schaub M, Reichlin TS, Abadi F, Kéry M, Jenni L, Arlettaz R. The demographic drivers of local population dynamics in two rare migratory birds. Oecologia. 2012; 168(1):97-108.

4. Bötsch Y, Arlettaz R, Schaub M. Breeding dispersal of Eurasian Hoopoes (Upupa epops) within and between years in relation to reproductive success, sex, and age. The Auk. 2012; 129(2):283-95.

5. Berthier K, Leippert F, Fumagalli L, Arlettaz R. Massive nest-box supplementation boosts fecundity, survival and even immigration without altering mating and reproductive behaviour in a rapidly recovered bird population. PloS one. 2012; 7(4):e36028.

6. Pärt T. The effects of territory quality on agedependent reproductive performance in the Northern wheatear, Oenanthe oenanthe. Anim Behav. 2001; 62(2):379-88.

7. Pasinelli G, Hegelbach J, Reyer HU. Spacing behavior of the middle spotted woodpecker in central Europe. J Wildlife Manage. 2001; 65(3):432-41. 
8. Cooper SJ. The thermal and energetic significance of cavity roosting in mountain chickadees and juniper titmice. Condor. 1999; 101(4):863-6.

9. Sunde $P, B ø l s t a d$ MS, Desfor KB. Diurnal exposure as a risk sensitive behaviour in tawny owls Strix aluco? J Avian Biol. 2003; 34(4):409-18.

10. Bock $A$, Naef-Daenzer B, Keil H, Korner-Nievergelt $F$, Perrig M, Grüebler MU. Roost site selection by little owls Athene noctua in relation to environmental conditions and life-history stages. Ibis. 2013; 155(4):847-56.

11. Mainwaring MC. The use of nestboxes by roosting birds during the non-breeding season: A review of the costs and benefits. Ardea. 2011; 99(2):167-76.

12. McClure CJ, Pauli BP, Heath JA. Simulations reveal the power and peril of artificial breeding sites for monitoring and managing animals. Ecol Appl. 2017; 27(4):1155-66.

13. Strasser EH, Heath JA. Reproductive failure of a human-tolerant species, the American kestrel, is associated with stress and human disturbance. J Appl Ecol. 2013; 50(4):912-19.

14. Murray BG. Measuring annual reproductive successin birds. Condor. 2000:102: 470-3.

15. Fournier J, Arlettaz R. Food provision to nestlings in the Hoopoe Upupa epops: Implications for the conservation of a small endangered population in the Swiss Alps. Ibis. 2001; 143(1):2-10.

16. Kristin A. Family Upupidae (Hoopoe). Handbook of the birds of the world. 2001; 6:396-411.

17. Camprodon J, Brotons L. Effects of undergrowth clearing on the bird communities of the Northwestern Mediterranean Coppice Holm oak forests. For Ecol Manage. 2006; 221(1):72-82.

18. Martín-Vivaldi M, Palomino JJ, Soler M, Soler J. Determinants of reproductive success in the Hoopoe Upupa epops, a hole-nesting non-passerine bird with asynchronous hatching. Bird Study. 1999; 46(2):20516.

19. Alerstam $T$, Högstedt $G$. Evolution of hole-nesting in birds. Ornis Scandinavica. 1981; 12(3):188-93.

20. Lack D. The significance of clutch-size. Ibis. 1947; 89(2):302-52.

21. Del-Hoyo J, Elliot A, Sargatal J. Mousebirds to Hornbills. Handbook of the birds of the World. 2001; 6.

22. Oehlschlaeger $\mathrm{S}$, Ryslavy T. Breeding biology of the Hoopoe Upupa epops on the former Military training areas near juterbog, brandenburg. Vogelwelt. 2002; 123:171-88. 